\title{
Isovolumic contraction time of right ventricle in d-transposition of great arteries ${ }^{\star}$
}

\author{
JEAN-CLAUDE FOURON, FRANÇOIS VALLOT, FRANÇOIS BOURLON, \\ MICHEL LOMBAERT, GILLES DUCHARME, ANDRÉ DAVIGNON
}

From the section of Cardiology, Departments of Pediatrics and Pediatric Research, Ste-fustine Hospital and University of Montreal, Canada

SUMMARY The pre-ejection period of the right ventricle in d-transposition of the great arteries is known to be prolonged, compared with the same interval of the left ventricle of normal subjects. In the present study, the echocardiographic measurement of the components of the pre-ejection period of the right ventricle of 14 patients with d-transposition of the great arteries shows that the isometric contraction time of the right ventricle in d-transposition of the great arteries is similar to the same interval calculated on the left ventricle of 76 normal children of comparable age. On the other hand, the electromechanical delay was significantly greater for the right ventricle of d-transposition of the great arteries than for the left ventricle of the normal subjects. It is concluded that the prolonged pre-ejection period of the right ventricle in d-transposition of the great arteries is not the result of right ventricular dysfunction but solely of a longer electromechanical delay.

In d-transposition of the great arteries (d-TGA), the right ventricle must maintain a normal output against the high resistance of the systemic circulation. Its ability to sustain this load throughout life has been seriously questioned since angiographic studies have shown that right ventricular enddiastolic volume is abnormally increased and the ejection fraction decreased, both before and after intra-atrial repair by the Mustard procedure. ${ }^{12}$

A recent publication on the assessment of myocardial function after Mustard's operation showed that the ratio of systolic time intervals for the right and left ventricles was appropriate for normal systemic and pulmonary ventricles, respectively. ${ }^{3}$ On the other hand most studies on myocardial function using systolic time intervals seem to be in agreement with volume measurements and have shown a prolonged right ventricular pre-ejection period and a shortened right ventricular ejection time in d-TGA suggesting that right ventricular function was depressed. ${ }^{4} 5$ However, these reports did not specify which part of the pre-ejection period, that is the electromechanical delay or the isovolumic contraction time, was responsible for prolonging the right ventricular pre-ejection period. Clarifica-

\footnotetext{
$\star$ Work supported in part by the Canadian Heart Foundations, La Fondation Justine-Lacoste-Beaubien and the MacDonald Stewart Foundation.
}

Received for publication 29 October 1979 tion of this point is essential before any conclusion can be drawn about the performance of the right ventricle. Indeed, isovolumic contraction time is the component of the pre-ejection period widely recognised as a reliable index of myocardial contractility. ${ }^{6}$ ?

The frequent clinical observation that postoperative patients with d-TGA achieve normal physical performance without any sign of cardiac failure, and the fact that a prolonged right ventricular pre-ejection period has been found right after birth in this disease, ${ }^{8}$ prompted us to investigate the possibility that in d-TGA, the right ventricular pre-ejection period was prolonged because of the lengthening of the right ventricular electromechanical delay.

\section{Subjects and methods}

Fourteen patients with d-TGA, surgically repaired by Mustard procedure, were included in this study. In all but two an atrial septostomy had been done previously. Their ages varied from $3 \frac{1}{2}$ to 16 years, with a mean of 7 years. Duration of follow-up after corrective surgery averaged three years and eight months (range: one to six years). They were all clinically asymptomatic. Associated lesions included mild pulmonary stenosis in two and a small ventricular septal defect in one. In all patients, the 
standard electrocardiogram showed right ventricular hypertrophy, without evidence of abnormal intraventricular conduction delay. Another group of 76 healthy children, aged $2 \frac{1}{2}$ to 16 years, with a mean of 8 years, was chosen for comparison.

In all cases echocardiograms were taken with an Echoline $20 \mathrm{~A}$ ultrasonoscope, coupled with a Cambridge fibreoptic recorder. An electrocardiographic lead with a well-identified $Q$ wave was simultaneously recorded. Systolic time intervals were measured according to techniques already described. ${ }^{5}$ The pre-ejection period of the systemic ventricle was calculated from the beginning of the $\mathrm{Q}$ wave on the electrocardiogram to the opening point of the aortic valve leaflets and identified as right ventricular pre-ejection period (RPEP) for the d-TGA group and left ventricular pre-ejection period (LPEP) for the normals. The corresponding isovolumic contraction time is, for the d-TGA, the difference between $Q$ to aortic valve opening and $\mathrm{Q}$ to tricuspid valve closure (RICT) (Fig), and for the normals, the difference between $Q$ to aortic valve opening and $Q$ to mitral valve closure (LICT). The electromechanical delay was calculated as RPEP less RICT (REMD), and LPEP less LICT (LEMD). In the group of normal subjects, the pre-

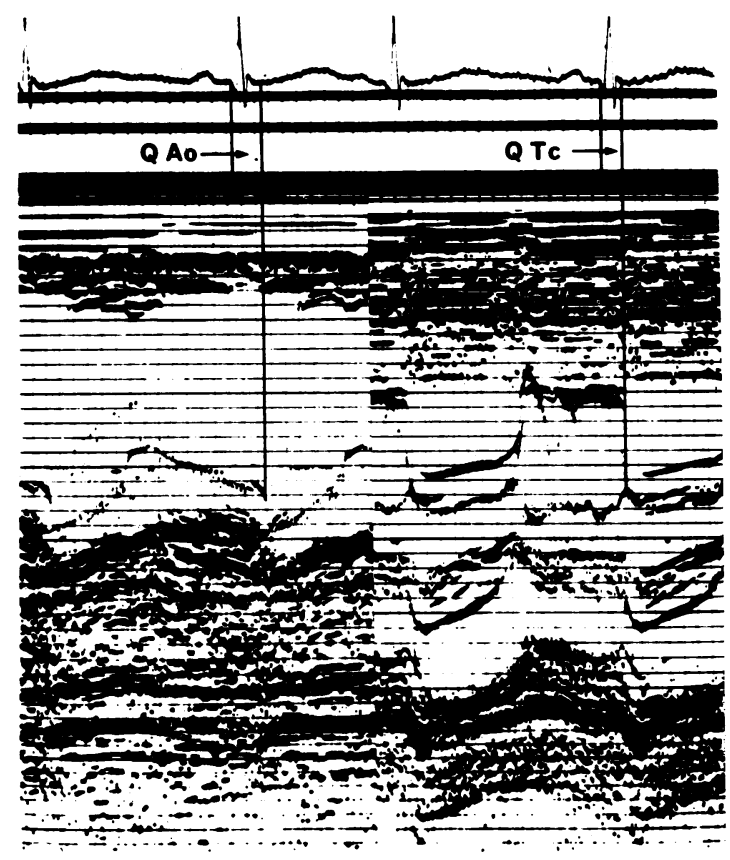

Fig. Composite of aortic and tricuspid echograms of a patient with $d-T G A$ showing the technique of measurement of $Q$ to aortic valve opening $(Q A o)$ and $Q$ to tricuspid valve closure $(Q T c)$. Isovolumic contraction time $=Q A o-Q T c$. ejection period of the right ventricle was measured from the beginning of the $Q$ wave to the opening point of the pulmonary valves; isovolumic contraction time was calculated as the difference of $Q$ to pulmonary valve opening less $Q$ to tricuspid valve closure, and electromechanical delay was the difference of the pre-ejection period less isovolumic contraction time. The paper speed was set as 100 $\mathrm{mm} / \mathrm{s}$, allowing measurement to the nearest $5 \mathrm{~ms}^{10}$ The average of at least five cardiac cycles was used in the calculations. Measurements were made at similar RR intervals.

In order to select the proper parametric tests for the statistical analysis of our materials, normality of the data was assessed by Lilliefors's test, ${ }^{11}$ and equality of variances by Bartlett's test. ${ }^{12}$ The Student's $t$ test was then used to evaluate the difference between right ventricular pre-ejection period of the d-TGA group and left ventricular preejection period of the normal subjects. A one-way analysis of variance with fixed effects was applied to compare the right ventricular isovolumic contraction time and electromechanical delay of patients with d-TGA, to the same intervals calculated on the left and right ventricular echocardiograms of the group of normal children. A contrast analysis using Scheffe's technique ${ }^{13}$ was applied to determine the means that were significantly different.

In the group of normal subjects, the regression equations of isovolumic contraction time and electromechanical delay versus heart rate yielded weak correlation coefficients $(r=0.44$ and 0.22 , respectively). This is in accordance with previous publications on the subject. ${ }^{914}$ For this reason, comparisons were made between values uncorrected for heart rate.

\section{Results}

Values found for the components of the pre-ejection period of the systemic right ventricle of the 14 children with d-TGA are given in the Table, as well as the mean values for the left and right ventricles of 76 normal subjects. The mean preejection period of the right ventricle of patients with d-TGA was significantly greater $(98 \mathrm{~ms}$, $\mathrm{SD}=13)$ than the same interval for the left ventricle of normal children $(79 \mathrm{~ms}, \mathrm{SD}=10)(\mathrm{p}<0.001)$. The right ventricular isovolumic contraction time of the d-TGA was not prolonged $(26 \mathrm{~ms}, \mathrm{SD}=5)$ when compared with values obtained in normal left ventricles $(33 \mathrm{~ms}, \mathrm{SD}=8)$. On the other hand, the electromechanical delay of the right ventricle in d-TGA averaged $72 \mathrm{~ms}(\mathrm{SD}=11)$, while the same interval measured on the left ventricle of normal children was $46 \mathrm{~ms} \quad(\mathrm{SD}=8)$. The difference 
between these two values is highly significant $(\mathrm{p}<0.001)$.

The average value of $72 \mathrm{~ms}$ found for the electromechanical delay of the right ventricle of patients with d-TGA was higher $(p<0.01)$ than that observed in the right ventricle of our group of normals $(60 \mathrm{~ms}, S D=9)$. The same observation can be made for the right ventricular isovolumic contraction time in d-TGA $(26 \mathrm{~ms}, \mathrm{SD}=5)$ and in normal subjects $(13 \mathrm{~ms}, \mathrm{SD}=8)(\mathrm{p}<0.01)$.

Table 1 Pre-ejection period and its components in systemic ventricle of patients with $d-T G A$ and in left and right ventricles of 76 normal children

\begin{tabular}{|c|c|c|c|c|}
\hline Case no. & Age (y) & $P E P$ (ms) & $I C T(\mathrm{~ms})$ & $E M D(m s)$ \\
\hline \multicolumn{5}{|c|}{ Patients with $d-T G A$} \\
\hline 1 & $3 \frac{1}{2}$ & 100 & 25 & 75 \\
\hline 2 & $4 \frac{1}{2}$ & 80 & 27 & 53 \\
\hline 3 & 5 & 100 & 20 & 80 \\
\hline 4 & 5 & 92 & 20 & 72 \\
\hline 5 & 5 & 105 & 25 & 80 \\
\hline 6 & 5 & 80 & 22 & 58 \\
\hline 7 & 5 & 78 & 28 & 50 \\
\hline 8 & 5 & 103 & 25 & 78 \\
\hline 9 & 7 & 105 & 30 & 75 \\
\hline 10 & 8 & 85 & 25 & 60 \\
\hline 11 & 9 & 118 & 38 & 80 \\
\hline 12 & 9 & 110 & 28 & 82 \\
\hline 13 & 10 & 105 & 25 & 80 \\
\hline 14 & 16 & 110 & 30 & 80 \\
\hline Mean & 7 & 98 (SD 13) & 26 (SD 5) & 72 (SD 11) \\
\hline \multicolumn{5}{|c|}{ Range: $3 \frac{1}{2}$ to 16} \\
\hline \multicolumn{5}{|c|}{$\begin{array}{l}\text { Normal children : } \\
\text { Mean }\end{array}$} \\
\hline LV & 8 & 79 (SD 10) & $33($ SD 8) & 46 (SD 8) \\
\hline \multicolumn{5}{|c|}{ Range: $2 \frac{1}{2}$ to 16} \\
\hline Mean & & & & \\
\hline RV & - & 73 (SD 9) & 13 (SD 8) & 60 (SD 9) \\
\hline
\end{tabular}

Abbreviations: PEP, pre-ejection period; ICT, isovolumic contraction time; EMD, electromechanical delay; SD, standard deviation; LV, left ventricle; RV, right ventricle.

\section{Comments}

The ability of the right ventricle to perform adequately as a systemic pump is crucial for the long-term prognosis of patients with d-TGA having undergone intra-atrial rerouting of the venous return. Previous angiographic studies have compared volumetric parameters of the right ventricle of patients with d-TGA with those of the right ventricle of normal individuals. Abnormal values were always found. ${ }^{1215}$ In fact, the question is how the right ventricle in d-TGA compares with the left ventricle of normal individuals. Such an approach has been applied in echocardiographic studies, where right ventricular systolic time intervals of d-TGA were compared with left ventricular intervals of normal subjects. In most of these studies, the conclusion that the right ventricular function was depressed in d-TGA, was based on finding a prolonged right ventricular pre-ejection period. ${ }^{4}$ The present study demonstrates that this conclusion is unwarranted. Indeed, the part of the pre-ejection period which closely correlates with measures of contractility, that is the isovolumic contraction time, is, in our group of d-TGA, similar to the same interval measured on the left ventricle of normal subjects. This finding is in full agreement with the normal pressure-velocity indices $(\mathrm{dP} / \mathrm{dt}$ and derived velocity variables) previously reported for the right ventricle of d-TGA. ${ }^{16}{ }^{17}$ The apparent contradiction between our results and the data presented in the angiographic reports may be explained by the work of Peterson and co-workers, ${ }^{18}$ who showed that changes in ejection fraction volumes and modification of the contractile state could occur independently of each other.

According to the present study, it is the prolongation of the right ventricular electromechanical delay which is responsible for the longer right ventricular pre-ejection period described in d-TGA when compared with the normal left ventricle. A previous report on time relation of dynamic events in the cardiac chambers, has documented a longer electromechanical delay for the right ventricle than for the left ventricle in normal hearts. ${ }^{19}$ Moreover, in our study, the right ventricular electromechanical delay in d-TGA has been found to be longer than that of normal right ventricles. This could be because of the greater myocardial mass of the hypertrophied right ventricle in d-TGA, resulting in a longer ventricular activation time. ${ }^{20}$

We believe that serial evaluation by systolic time intervals of right ventricular function in d-TGA should be based on the measurement of the isovolumic contraction time in preference to that of the complete pre-ejection period.

\section{References}

1 Graham TP, Atwood GF, Boucek RJ, Boerth RC, Nelson JH. Right heart volume characteristics in transposition of the great arteries. Circulation 1975; 51: 881-9.

2 Graham TP, Atwood GF, Boucek RJ, Boerth RC, Bender HW. Abnormalities of right ventricular function following Mustard's operation for transposition of the great arteries. Circulation 1975; 52: 678-84.

3 Silverman NH, Payot M, Stanger P, Rudolph AM. The echocardiographic profile of patients after Mustard's operation. Circulation 1978; 58: 1083-93.

4 Korf hagen J, Meyer R, Kaplan S. Non-invasive assessment of right ventricular performance in transposition of the great arteries (abstract). $A m \mathcal{F}$ Cardiol 1977; 39: 310.

5 Hirschfeld S, Meyer R, Schwartz DC, Korf hagen J, Kaplan S. Measurement of right and left ventricular 
systolic time intervals by echocardiography. Circulation 1975; 51: 304-9.

6 Ahmed SS, Levinson GE, Schwartz CJ, Ettinger PO. Systolic time intervals as measures of the contractile state of the left ventricular myocardium in man. Circulation 1972; 46: 559-71.

7 Mason DT. Usefulness and limitations of the rate of rise of intraventricular pressure $(\mathrm{dP} / \mathrm{dt})$ in the evaluation of myocardial contractility in man. $A m \mathcal{F}$ Cardiol 1969; 23: 516-27.

8 Fouron JC, Lombaert M, Payot M, Davignon A. Systolic time intervals during the first hours of life in D-transposition of the great arteries (abstract). Can Cardiovasc Soc, 30th Annual Meeting, Toronto.

9 Hirschfeld S, Meyer R, Korf hagen J, Kaplan S, Liebman J. The isovolumic contraction time of the left ventricle. An echographic study. Circulation 1976; 54: 751-6.

10 Spodick DH, Ball HG, Pigott VM. Effects of recording speed on precision of time-based polycardiographic measurements. Optimal paper speeds for measuring points and intervals. $\mathrm{Br}$ Heart $\mathcal{f} 1978$; 40: $1344-8$.

11 Lilliefors HW. On the Kolmogorov-Smirnov test for normality with mean and variance unknown. F Am Stat Assoc 1967; 62: 399-402.

12 Winer BJ. Statistical principles in experimental design. 2nd ed. New York: McGraw-Hill, 1971: 207.

13 Scheffe $H$. The analysis of variance. New York: John Wiley, 1959: 68.

14 Spitaels S, Arbogast R, Fouron JC, Davignon A.
The influence of heart rate and age on the systolic and diastolic time intervals in children. Circulation 1974; 49: 1107-15.

15 Jarmakani JM, Canent RV. Preoperative and postoperative right ventricular function in children with transposition of the great vessels. Circulation 1974; 49 and 50, suppl II : 39-45.

16 Godman MJ, Friedli B, Pasternac A, Kidd BSL, Trusler GA, Mustard WT. Hemodynamic studies in children four to ten years after the Mustard operation for transposition of the great arteries. Circulation 1976; 53: 532-8.

17 Pasternac A, Hawker RE, Kidd L. Right and left ventricular function in complete transposition of the great arteries (abstract). Am $\mathcal{F}$ Cardiol 1973; 31: 152.

18 Peterson KL, Skloven D, Ludbrook P, Uther JB, Ross J Jr. Comparison of isovolumic and ejection phase indices of myocardial performance in man. Circulation 1974; 49: 1088-101.

19 Braunwald E, Fishman AP, Cournand A. Time relationship of dynamic events in the cardiac chambers, pulmonary artery and aorta in man. Circ Res 1956; 4: 100-7.

20 Scott RC. The correlation between the electrocardiographic patterns of ventricular hypertrophy and the anatomic findings. Circulation 1960; 21: 256-91.

Requests for reprints to Dr Jean-Claude Fouron, Ste-Justine Hospital, 3175 Ste-Catherine Road, Montreal, Quebec H3T 1C5, Canada. 